\title{
$\$$ Research Square

\section{Factors associated with screening for preeclampsia in the Democratic Republic of Congo: evidence from a nationwide cross-sectional study}

Dalau Mukadi Nkamba ( $\sim$ dalau.nkamba@unikin.ac.cd)

Université catholique de Louvain (UCLouvain), Institut de Recherche Expérimentale et Clinique (IREC)

Gilbert Wembodinga

University of Kinshasa

Pierre Bernard

Université catholique de Louvain (UCLouvain), Institut de Recherche Expérimentale et Clinique (IREC), Cliniques universitaires Saint-Luc

Annie Robert

Université catholique de Louvain (UCLouvain), Institut de Recherche Expérimentale et Clinique (IREC)

\section{Research Article}

Keywords: Screening, Preeclampsia, DR Congo

Posted Date: June 15th, 2021

DOI: https://doi.org/10.21203/rs.3.rs-559506/v1

License: (9) This work is licensed under a Creative Commons Attribution 4.0 International License. Read Full License 


\section{Abstract}

\section{Background}

Delays in identification of women with preeclampsia is a contributing factor to maternal deaths in developing countries. We conducted this study to assess the prevalence of screening for preeclampsia in the Democratic Republic of Congo (DRC), and to identify factors associated with the screening.

\section{Methods}

We used data from the 2017-2018 DRC Service Provision Assessment survey, a nationwide survey that samples services, including antenatal care (ANC), in representative health facilities. A pregnant woman was deemed screened for preeclampsia if she had received the two following services: blood pressure measurement and assessment for warning signs of preeclampsia. We used multiple logistic regression, with generalized estimating equations, to identify factors associated with screening for preeclampsia.

\section{Results}

Of the 3763 pregnant women, $719(19.1 \% ; 95 \% \mathrm{Cl}, 15.8 \%$ - 22.9\%) were screened for preeclampsia, 815 $(21.7 \% ; 95 \% \mathrm{Cl}, 18.2 \%-25.6 \%)$ were assessed for preeclampsia-related warning signs and symptoms, and 2941 (78.2\%; 95\% Cl 73.6 - 82.1\%) had their blood pressure checked.

In multivariable analyses, the percentage of women receiving screening for preeclampsia was significantly higher among women with a secondary level of schooling or above (adjusted odds ratio $[A O R]=1.21 ; 95 \% \mathrm{Cl}, 1.04-1.42 ; \mathrm{P}=0.016)$ and among women having a subsequent $A N C$ visit $(\mathrm{AOR}=1.39$; $95 \% \mathrm{Cl}, 1.20-1.62 ; \mathrm{P}<0.001)$. It was also higher among women receiving care in facilities with a low number of women attended per day $(A O R=1.28 ; 95 \% \mathrm{Cl}, 1.09-1.51 ; \mathrm{P}=0.003)$ and in urban settings $(\mathrm{AOR}=1.36 ; 95 \% \mathrm{Cl}, 1.02-1.82 ; \mathrm{P}=0.036)$.

There was a regional variation in the screening for preeclampsia, with the lowest prevalence observed in the Central (10.7\%) and the highest in the Eastern provinces (22.5\%).

\section{Conclusion}

Our study shows that screening for preeclampsia during ANC visits in DRC is not systematic, with disparities between provinces. We found that a low schooling level, a low number of ANC visits, rural areas, province of residence, and a high volume of ANC visits at the facility were associated with a low screening for preeclampsia. These factors should be considered for setting up strategies in order to increase the screening for preeclampsia during ANC visits in provinces of DRC with too low screening.

\section{Background}


Hypertensive Disorders in Pregnancy (HDP) including preeclampsia are the leading cause of direct maternal deaths worldwide (1). Globally, preeclampsia affects 2 to $8 \%$ of pregnancies annually, and is responsible for over 50000 maternal deaths (2). Most of deaths occur in low- and middle-income countries (LMICs) and are however preventable. A contributing factor in these deaths is a delay in identifying preeclamptic women (3-7).

Screening for preeclampsia after 20 weeks of gestation, including blood pressure measurement and inquiring about preeclampsia-related danger signs, is an important component of the antenatal care (ANC) (8-13). Screening should occur during each ANC visit to allow early detection of preeclampsia and to implement appropriate care for improving maternal and perinatal outcomes $(8,14-20)$.

However, a study from six sub-Saharan Africa countries indicated that only $31 \%$ of ANC attendees are screened for preeclampsia (21).

According to the World Health Organization (WHO), maternal mortality in the DRC is estimated to be 473 deaths per 100000 live births (22), despite a high rate of both skilled attendance at delivery (80\%) and antenatal care attendance (89\%) (23). The contrast between the high maternal mortality rate and the high antenatal service coverage may indicates that the majority of antenatal attendees miss screening for clinical conditions, such as preeclampsia, known to result in poor birth outcomes $(24,25)$.

According to the DRC's National Health Information System (NHIS), $3379(62 \%)$ of the 5459 cases of preeclampsia reported in DRC in 2019 developed eclampsia (28), the major cause of deaths due to HDPs. Studies focusing on the screening for preeclampsia in DRC are scarce. A previous study assessed the screening for HDP in Kinshasa, the capital city of DRC, by combining proteinuria testing, blood pressure measurement, and a comprehensive maternal history as a screening package. The study indicated that only $26.7 \%$ of pregnant women were screened for HDP (25).

A services provision assessment survey was conducted in DRC (DRC-SPA) from 2017 to 2018 to evaluate the quality of healthcare services nationwide (13).

Data from the DRC-SPA survey have been used to assess the provision of individual screening tasks for preeclampsia including blood pressure measurement and inquiring about warning signs of preeclampsia. However, no study to date has assessed the provision of these individual tasks during ANC visit as a screening package nationwide in DRC. Our study therefore aims to fill this gap by using data from the DRC-SPA survey to assess the frequency of screening for preeclampsia nationwide in DRC and to identify factors associated with the screening.

\section{Methods}

\section{Data source}

We used data from the 2017-18 DRC-SPA survey, a nationwide facility-based cross-sectional study. The survey was implemented by the Kinshasa School of Public Health (KSPH) with technical assistance from 
Inner City Fund International through funding from the United States Agency for International Development (USAID).

\section{Sample size and sampling procedure}

The sampling process for the DRC-SPA survey has been described in details elsewhere (26). Briefly, the survey sampled 1412 health facilities of which 32 could not be reached due to their location in areas where there were still armed conflicts. As a result, 1380 health facilities were surveyed, of which 1286 offered an ANC visit during the study period. In each health facility, five women per ANC provider were included in the survey with a maximum of 15 women per facility. The final sample size was 4512 women. As preeclampsia rarely presents prior to 20 weeks' gestation (27), we excluded women with a gestational age less than 20 weeks $(n=749)$. As a result, 3763 pregnant women were included in the analytic sample. These women received care from 1191 providers in 864 health facilities (Figure 1). Data were collected between October 16, 2017 and November 24, 2017 in Kinshasa, and from January 18, 2018 to April 20, 2018 in the rest of the DRC.

The survey used four data collection tools: 1) facility inventory questionnaire; 2) healthcare provider interview questionnaire; 3 ) checklist for direct observation of services for sick children, family planning, and ANC; and 4) exit interview questionnaires for caretakers of sick children, for women receiving ANC and for women receiving family planning whose consultations were observed.

For each pregnant woman, a data collector observed the provider conducting ANC consultation and recorded observations using the ANC observation checklist. Specifically, the data collector observed whether the provider measured blood pressure, tested or referred the woman for proteinuria testing, or asked about any preeclampsia-related warning signs, including severe headaches or blurred vision, and swollen face or hands. The data collector also observed whether the woman herself mentioned any of these preeclampsia-related warning signs to the provider.

At the completion of ANC consultation, data collectors interviewed the women to collect sociodemographic and reproductive data. Data collectors also collected clinic-level data such as the type of clinics (private or public), location (urban or rural), as well as data regarding the quality of health providers who attended pregnant women (specifically, whether they had received in-service training in the management of HDP or not).

\section{Operational definitions}

We used the following definitions:

Preeclampsia screening package

The entire preeclampsia screening package consisted of 1) inquiring about preeclampsia-related warning signs, and 2) blood pressure measurement $(21,28)$. 
ANC provider asked about or the woman mentioned any of the following conditions for current pregnancy: headaches or blurred vision, swollen face or hands.

\section{Woman screened for preeclampsia}

A pregnant woman who had received the entire preeclampsia screening package during the ANC visit.

\section{Data processing and management}

For the purpose of analyses, we merged four datasets (facility inventory, provider interview, direct observation of ANC consultation, and exit interview datasets) into one dataset by using the provider and facility identifiers of each dataset. The unit of analysis of the merged dataset was individual women. Secondary and tertiary health facilities were grouped into one category named "hospitals", as they are all used as referral by primary health centres (PHCs).

\section{Data analysis}

Data were analyzed using Stata 14.1 software (StataCorp, College Station, Texas). All analyses were weighted using sampling weights provided in the DRC-SPA datasets. Continuous variables were summarized using weighted mean and standard deviation $( \pm S D)$ if normally distributed, and median and interquartile range (IQR) otherwise. Categorical variables were summarized using weighted proportions.

Screening for preeclampsia was our major outcome. We used generalized estimating equations (GEE) method while fitting a logistic regression model to adjust for correlation among pregnant women of the same clinic. All variables with a P-value less than 0.25 in univariate analysis were included in the multivariable analysis.

Explanatory variables included characteristics of women (schooling level, gestational age, number of previous ANC visits for the current pregnancy, gravidity, province of residence), provider characteristics (qualification, whether he/she received in-service training on ANC screening within the previous 24 months), and facility characteristics (location, facility type, facility ownership, mean number of pregnant women attended per day). Quantitative independent variables, such as the mean number of ANC visit per health facility per day, were standardized to avoid scale dependence. If a strong correlation was noticed between two independent variables, one amongst the two was eliminated to avoid multicollinearity. We checked multicollinearity among independent variables by estimating the variance inflation factor (29). All variance inflation factor values were less than 10 . Therefore, no multicollinearity was observed. The statistical significance level was set to 0.05 .

\section{Results}

\section{Characteristics}


Of the 864 health facilities, 319 (36.9\%) were PHCs and 545 (63.1\%) were hospitals. About three quarters of facilities (633[73.3\%]) were in rural settings. Half of facilities attended less than 8 pregnant women per day (median: 8 [IQR: 3 to 15]), and most ANC providers were midwives (87.2\%).

Pregnant women were observed at a median gestational age of 28 weeks (IQR: 24-32 weeks). A majority of pregnant women had a primary level of schooling or less (56.3\%), received ANC in rural facilities (74.3\%), and were multigravida (74.4\%) (Table 1).

\section{Screening status for preeclampsia}

Of the 3763 pregnant women, $719(19.1 \% ; 95 \% \mathrm{Cl}, 15.8 \%$ - 22.9\%) were screened for preeclampsia, 815 $(21.7 \% ; 95 \% \mathrm{Cl}, 18.2 \%-25.6 \%)$ were assessed for preeclampsia-related warning signs, and 2941 (78.2\%; $95 \% \mathrm{Cl}, 73.6 \%-82.1 \%)$ had their blood pressure checked. Inquiring about warning signs was poorly performed by ANC providers, with $17 \%$ of pregnant women asked about headache or blurred vision, $9.7 \%$ asked about swollen hands or face, and $21.7 \%$ asked about any sign.

One fifth of women $(19.8 \% ; 95 \% \mathrm{Cl}, 16.0 \%-24.1 \%)$ had either urine testing for proteinuria or were referred for the test. The prevalence of urine testing for proteinuria ranged from $3.9 \%$ in Kasai Oriental to $36.0 \%$ in Kinshasa (Table 2).

There were provincial disparities in the screening for preeclampsia, with the lowest percentage of women screened in provinces such as Maniema (8.0\%); , and Bandundu (8.7\%), and the highest percentage in Nord Kivu (38.3\%); (Figure 2).

Overall there was no difference in screening for preeclampsia in public compared to private facilities, and no difference between PHCs and hospitals. However, in Katanga and Bandundu, screening for preeclampsia was higher in private compared to public facilities. A higher percentage of women were screened in hospitals compared to PHCs in Katanga Province (Table 3).

\section{Factors associated with screening for preeclampsia}

In multivariable analyses, the percentage of women screened for preeclampsia was significantly higher among women with secondary level of schooling or above (adjusted odds ratio $[\mathrm{AOR}]=1.21 ; 95 \% \mathrm{Cl}$, 1.04-1.42; $P=0.016)$ and among women having a subsequent $A N C$ visit $(A O R=1.39 ; 95 \% \mathrm{Cl}, 1.20-1.62$; $P<0.001)$. It was also higher among those receiving care in facilities with a low number of ANC visits $(A O R=1.28 ; 95 \% \mathrm{Cl}, 1.09-1.51 ; \mathrm{P}=0.003)$ and in urban settings $(\mathrm{AOR}=1.36 ; 95 \% \mathrm{Cl}, 1.02-1.82 ; \mathrm{P}=0.036$

There was a regional variation in the screening for preeclampsia, with the lowest prevalence observed in the Central (10.7\%) and the highest in the Eastern provinces (22.5\%). (Table 4).

\section{Discussion}


We conducted the current study to assess the prevalence of screening for preeclampsia and to identify factors associated with the screening nationwide in DRC. Our study revealed low provision of screening for preeclampsia in DRC, with only $19.1 \%$ of women fully screened. Screening for preeclampsia was significantly higher in women with at least secondary level of schooling, in women attending a first ANC visit, or in those receiving care in a facility with a low number of ANC visits, or among women living in an urban area.

Among women in whom screening was not completed, about one-quarter did not have blood pressure measured. However, failure to inquire about preeclampsia-related warning signs was a more common gap in quality; it was not performed in nearly three-quarters of women. This appears to be a common concern in other Sub-Saharan African countries such as Rwanda (70\%), Ethiopia (62\%), and Madagascar (53\%) (21).

Preeclampsia-related warning signs can be ascertained by a simple anamnesis of a pregnant woman during ANC visit (17). The failure to assess women for preeclampsia-related warning signs in DRC may be a consequence of providers' knowledge gaps and/or lack of motivation or supervision, but the point needs further investigations.

Although heavy ANC workload could be another explanation for this failure, this is unlikely given that health facilities included in our study had relatively low volumes of ANC attendees on the day of the survey, as half of them received less than 8 ANC visits per day.

Our study found a low provision of urine testing for proteinuria (19.8\%). Unlike the WHO recommendations, the current national ANC guidelines in DRC do not recommend systematic urine testing for proteinuria during ANC visits. The guidelines recommend proteinuria screening in women with warning signs of preeclampsia (30). As preeclampsia can present with isolated proteinuria $(31,32)$, it is essential that DRC move towards universal urine testing for proteinuria at every ANC visit.

The proportion of women screened for preeclampsia in DRC is similar to findings from Rwanda (22\%), but lower than the range of $24 \%$ to $55 \%$ reported in other developing countries such as Madagascar, Tanzania and Ethiopia (21). We found disparities in screening for preeclampsia between provinces, with the highest prevalence in Nord Kivu (38.4\%), and the lowest in Maniema (7.9\%). We speculate that inequity in the distribution of international agencies involved in maternal health in DRC, with Nord Kivu having the highest number of donors (33), may result in disparities in the provision of health services including screening for preeclampsia. However, additional information is needed to further understand the disparities in screening for preeclampsia between provinces. Information on ANC providers' motivation and satisfaction or the quality of their supervision would be helpful next steps to contextualize results found in this analysis.

According to a previously published study, only $9.1 \%$ of health facilities in DRC provide quality emergency obstetric care services, including parenteral administration of magnesium sulfate (34). In the setting of scarce emergency care, universal screening for preeclampsia may be of paramount public health 
importance because early identification of women with preeclampsia allows timely referral of the woman to a facility with appropriate care. However, our findings indicate that women with ANC visits in rural settings were less likely to be screened than those in urban areas. This finding is in line with other studies reporting a low provision of ANC services in rural compared to urban settings (35). Furthermore, our findings indicate that women attending a subsequent ANC visit are more likely to be screened than those attending a first visit. As a result, women with preeclampsia may not be identified at an early stage of pregnancy. In DRC, a number of pregnant women have only one ANC visit $(36,37)$. For these women, the first ANC visit may also be the last one. Therefore, ANC providers should provide all recommended screenings, including screening for preeclampsia, without waiting for the next visit which may not take place.

Screening for preeclampsia was significantly higher among women with secondary or higher level of schooling than those with primary or no level of schooling. This finding is consistent with others studies that reported a high provision of ANC services among more educated women $(38,39)$. It is possible that health providers discriminate against women with low level of schooling by not providing all the required antenatal services $(39,40)$. Moreover, women with high level of schooling may be more knowledgeable about obstetric danger signs including warning signs of preeclampsia and are thus more likely to mention them during ANC visits than women with lower level of schooling (41).

The prevalence of screening for preeclampsia was significantly lower in facilities with higher volumes of ANC visits in a given day. As a result, researchers have suggested task shifting as an alternative to improve screening for maternal conditions, including preeclampsia (42).

The low provision of screening for preeclampsia in DRC may also be due to lack of consistent national guidelines on the prevention of preeclampsia, which can subsequently induce knowledge gaps among ANC providers. As in other African countries, the current national guidelines in DRC offer little guidance on preventing preeclampsia in ANC services $(30,43)$.

This low provision of screening for preeclampsia in DRC may result in missed opportunities to identify women with preeclampsia as early as possible to prevent adverse maternal and perinatal outcomes. With such low provision of screening, it is not unexpected that preeclampsia is still a public health problem in DRC $(29,44)$. This study has provided information on the factors that should be addressed in strategies aimed at improving screening for preeclampsia in DRC.

The strength of the present study was the use of a comprehensive national dataset, suggesting that our findings accurately reflect the current situation regarding the quality of screening for preeclampsia in DRC.

The study also has some limitations. Because screening for preeclampsia was assessed by direct observation, health providers might have made an extra effort to give their best quality service at the time when the research team visited the clinic. This Hawthorne effect was mitigated by having up to five 
observations per provider, which may have helped to reduce providers' awareness of the presence of the data collector.

\section{Conclusion}

Our study shows that screening for preeclampsia during ANC visits in DRC is not systematic. The gap in the quality of screening was in both blood pressure measurement and assessing women for warning signs of preeclampsia. We found that a low schooling level, a low number of ANC visits, rural areas, province of residence, and a high volume of ANC visits at the facility were associated with a low screening for preeclampsia. These factors should be considered for setting up strategies in order to increase the screening for preeclampsia during ANC visits in provinces of DRC with too low

\section{Abbreviations}

ANC: Antenatal care; AOR: Adjusted odds ratio; Cl: confidence interval; DHS: Demographic and Health Survey; DRC: Democratic Republic of Congo; GEE: generalized estimating equations; HDP: Hypertensive Disorders in Pregnancy; IQR: interquartile range; LMIC: Low- and Middle-Income Countries; NHIS: National Health Information System; OR: Crude odds ratio; SD: standard deviation.

\section{Declarations}

\section{Ethics approval and consent to participate}

The DRC-SPA survey was approved by the institutional review board of the

Kinshasa School of Public Health. We obtained permission to use the survey data from the Measure Demographic Health Survey Program. Further ethical approval was not required, as our research is a secondary data analysis of publicly available datasets that do not include any identifiable information that links to the survey participants.

\section{Consent for publication}

Not applicable

\section{Availability of data and material}

The DRC-SPA data is publically available from the DHS website: http://dhsprogram.com/data/availabledatasets.cfm

\section{Competing interests}

The authors declare that they have no competing interests.

\section{Funding}


None

\section{Authors' contributions}

DNM and AR designed the research; DNM analyzed data, and drafted the manuscript. AR, GW, and PB critically revised the drafted manuscript. All authors read and approved the final manuscript.

\section{Acknowledgments}

We are thankful to the DHS program for data accessibility. We also thank Professor Carl Bose and Patrick Arena for their useful inputs on the manuscript.

\section{References}

1. Kinney MV, Kerber KJ, Black RE, Cohen B, Nkrumah F, Coovadia H, et al. Sub-Saharan Africa's Mothers, Newborns, and Children: Where and Why Do They Die? PLoS Med. 2010;7(6).

https://www.ncbi.nlm.nih.gov/pmc/articles/PMC2888581/ Accessed 10 May 2021

2. Duley L. Maternal mortality associated with hypertensive disorders of pregnancy in Africa, Asia, Latin America and the Caribbean. Br J Obstet Gynaecol. 1992;99(7):547-53.

3. Moodley J. Maternal deaths due to hypertensive disorders in pregnancy. Best Pract Res Clin Obstet Gynaecol. 2008;22(3):559-67

4. Ghulmiyyah L, Sibai B. Maternal mortality from preeclampsia/eclampsia. Semin Perinatol. 2012;36(1):56-9.

5. Firoz T, Sanghvi H, Merialdi M, von Dadelszen P. Pre-eclampsia in low and middle income countries. Best Pract Res Clin Obstet Gynaecol. 2011;25(4):537-48.

6. Goldenberg RL, Jones B, Griffin JB, Rouse DJ, Kamath-Rayne BD, Trivedi N, et al. Reducing maternal mortality from preeclampsia and eclampsia in low-resource countries-what should work? Acta Obstet Gynecol Scand. 2015;94(2):148-55. https://obgyn.onlinelibrary.wiley.com/doi/full/10.1111/aogs.12533 Accessed 10 May 2021

7. Goldenberg RL, McClure EM, Macguire ER, Kamath BD, Jobe AH. Lessons for low-income regions following the reduction in hypertension-related maternal mortality in high-income countries. Int $\mathrm{J}$ Gynaecol Obstet Off Organ Int Fed Gynaecol Obstet. 2011;113(2):91-5.

8. Committee Opinion No. 638: First-Trimester Risk Assessment for Early-Onset Preeclampsia. Obstet Gynecol. $2015 ; 126(3)$ : e25.

https://journals.Iww.com/greenjournal/Fulltext/2015/09000/Committee_Opinion_No 638

First_Trimester_Risk.49.aspx Accessed 10 May 2021 
9. Redman CWG. Hypertension in pregnancy: the NICE guidelines. Heart Br Card Soc. 2011;97(23):1967-9. https://www.ncbi.nlm.nih.gov/pubmed/21990386 Accessed 10 May 2021

10. Visintin C, Mugglestone MA, Almerie MQ, Nherera LM, James D, Walkinshaw S, et al. Management of hypertensive disorders during pregnancy: summary of NICE guidance. BMJ. $2010 ; 341$ :c2207. https://www.ncbi.nlm.nih.gov/pubmed/20739360 Accessed 10 May 2021

11. World Health Organization. WHO Recommendations on Antenatal Care for a Positive Pregnancy Experience. Geneva: World Health Organization; 2016. (WHO Guidelines Approved by the Guidelines Review Committee). http://www.ncbi.nlm.nih.gov/books/NBK409108/ Accessed 10 May 2021

12. Magee LA, Pels A, Helewa M, Rey E, von Dadelszen P, Canadian Hypertensive Disorders of Pregnancy Working Group. Diagnosis, evaluation, and management of the hypertensive disorders of pregnancy: executive summary. J Obstet Gynaecol Can JOGC J Obstet Gynecol Can JOGC. 2014;36(5):416-41. https://www.ncbi.nlm.nih.gov/pubmed/24927294 Accessed 10 May 2021

13. Brown MA, Magee LA, Kenny LC, Karumanchi SA, McCarthy FP, Saito S, et al. The hypertensive disorders of pregnancy: ISSHP classification, diagnosis \& management recommendations for international practice. Pregnancy Hypertens. 2018; 13:291-310.

14. Rolnik DL, Wright D, Poon LC, O'Gorman N, Syngelaki A, de Paco Matallana C, et al. Aspirin versus Placebo in Pregnancies at High Risk for Preterm Preeclampsia. N Engl J Med. 2017;377(7):613-22. https://www.nejm.org/doi/full/10.1056/NEJMoa1704559 Accessed 10 May 2021

15. Greene MF, Solomon CG. Aspirin to Prevent Preeclampsia. N Engl J Med. 2017;377(7):690-1. https://www.nejm.org/doi/full/10.1056/NEJMe1708920 Accessed 10 May 2021

16. Moore GS, Allshouse AA, Post AL, Galan HL, Heyborne KD. Early initiation of low-dose aspirin for reduction in preeclampsia risk in high-risk women: a secondary analysis of the MFMU High-Risk Aspirin Study. J Perinatol. 2015;35(5):328-31. https://www.ncbi.nlm.nih.gov/pmc/articles/PMC4838902/ Accessed 10 May 2021

17. Rolnik D. L., O'Gorman N., Roberge S., Bujold E., Hyett J., Uzan S., et al. Early screening and prevention of preterm pre-eclampsia with aspirin: time for clinical implementation. Ultrasound Obstet Gynecol. 2017;50(5):551-6. https://obgyn.onlinelibrary.wiley.com/doi/full/10.1002/uog.18899 Accessed 10 May 2021

18. Okusanya BO, Oladapo OT, Long Q, Lumbiganon P, Carroli G, Qureshi Z, et al. Clinical pharmacokinetic properties of magnesium sulphate in women with pre-eclampsia and eclampsia. BJOG Int J Obstet Gynaecol. 2016;123(3):356-66. https://www.ncbi.nlm.nih.gov/pmc/articles/PMC4737322/ Accessed 10 May 2021 
19. Khooshideh M, Ghaffarpour M, Bitarafan S. The comparison of anti-seizure and tocolytic effects of phenytoin and magnesium sulphate in the treatment of eclampsia and preeclampsia: A randomised clinical trial. Iran J Neurol. 2017 ;16(3):125-9. https://www.ncbi.nlm.nih.gov/pmc/articles/PMC5673984/ Accessed 10 May 2021

20. Mone F, Mulcahy C, McParland P, McAuliffe FM. Should we recommend universal aspirin for all pregnant women? Am J Obstet Gynecol. 2017;216(2):141.e1-

141.e5. https://www.ncbi.nlm.nih.gov/pubmed/27659212 Accessed 10 May 2021

21. Rawlins B, Plotkin M, Rakotovao JP, Getachew A, Vaz M, Ricca J, et al. Screening and management of pre-eclampsia and eclampsia in antenatal and labor and delivery services: findings from cross-sectional observation studies in six sub-Saharan African countries. BMC Pregnancy Childbirth. 2018;18(1):346. https://www.ncbi.nlm.nih.gov/pmc/articles/PMC6108136/ Accessed 10 May 2021

22. WHO. Trends in maternal mortality 2000 to 2017: estimates by WHO, UNICEF, UNFPA, World Bank Group and the United Nations Population Division. Geneva: World Health Organization; 2019. http://www.who.int/reproductivehealth/publications/maternal-mortality-2000-2017/en/ Accessed 10 May 2021

23. The DHS Program - Quality information to plan, monitor and improve population, health, and nutrition programs. https://www.dhsprogram.com/ Accessed 10 May 2021

24. Tandu-Umba B, Mbangama MA, Kamongola KMB, Kamgang Tchawou AG, Kivuidi MP, Kasonga Munene S, et al. Pre-pregnancy high-risk factors at first antenatal visit: how predictive are these of pregnancy outcomes? Int J Womens Health. $2014 ; 6: 1011-8$.

https://www.ncbi.nlm.nih.gov/pmc/articles/PMC4266255/ Accessed 10 May 2021

25. Nkamba DM, Ditekemena J, Wembodinga G, Bernard P, Tshefu A, Robert A. Proportion of pregnant women screened for hypertensive disorders in pregnancy and its associated factors within antenatal clinics of Kinshasa, Democratic Republic of Congo. BMC Pregnancy Childbirth. $2019 ; 19(1): 297$. https://doi.org/10.1186/s12884-019-2435-z Accessed 10 May 2021

26. École de Santé Publique, Université de Kinshasa, ICF. Évaluation de la Prestation des Services de Soins de Santé 2017-2018: Rapport de synthèse. Rockville, Maryland, USA: ESPK et ICF; 2019.

27. Tanaka M, Tsujimoto Y, Goto K, Kumahara K, Onishi S, Iwanari S, et al. Preeclampsia before 20 weeks of gestation: a case report and review of the literature. CEN Case Rep 2014;4(1):55-60. https://www.ncbi.nlm.nih.gov/pmc/articles/PMC5411624/ Accessed 10 May 2021

28. Bazant E, Rakotovao JP, Rasolofomanana JR, Tripathi V, Gomez P, Favero R, et al. Quality of care to prevent and treat postpartum hemorrhage and pre-eclampsia/eclampsia: an observational assessment in Madagascar's hospitals. Med Sante Trop. 2013;23(2):168-75. 
29. Kleinbaum DG, Kupper LL, Muller KE, Nizam A. Applied Regression Analysis and Other Multivariable Methods. 4th edition. Australia; Belmont, CA:Duxbury Press; 2007.

30. République Démocratique du Congo, Ministère de la Santé Publique. Normes et directives des interventions intégrées de santé de la mère, du nouveau-né et de l'enfant en République Démocratique du Congo. Volume 1 soins: obstétricaux essentiels. Kinshasa; 2012.

31. Akaishi R, Yamada T, Morikawa M, Nishida R, Minakami H. Clinical features of isolated gestational proteinuria progressing to pre-eclampsia: retrospective observational study. BMJ Open. 2014;4(4): e004870.

32. Shinar S, Asher-Landsberg J, Schwartz A, Ram-Weiner M, Kupferminc MJ, Many A. Isolated proteinuria is a risk factor for pre-eclampsia: a retrospective analysis of the maternal and neonatal outcomes in women presenting with isolated gestational proteinuria. J Perinatol Off J Calif Perinat Assoc. 2016 ;36(1):25-9.

33. République Démocratique du Congo, Ministère de la Santé Publique. Rapport final cartographie de la SMNE. Kinshasa 2012. http://familyplanningdrc.net/docs/Rapport\%20final\%20cartographie\%20de\%20la\%20SMNE\%2029\%20octobre\%202012.pdf Accessed 10 May 2021

34. Mpunga Mukendi D, Chenge F, Mapatano MA, Criel B, Wembodinga G. Distribution and quality of emergency obstetric care service delivery in the Democratic Republic of the Congo: it is time to improve regulatory mechanisms. Reprod Health. 2019;16.

https://www.ncbi.nlm.nih.gov/pmc/articles/PMC6631736/ Accessed 10 May 2021

35. Arsenault C, Jordan K, Lee D, Dinsa G, Manzi F, Marchant T, et al. Equity in antenatal care quality: an analysis of 91 national household surveys. Lancet Glob Health. 2018;6(11):e1186-95.

36. Institut national de la statistique. Enquête par grappes à indicateurs multiples, 2017-2018, rapport de résultats de l'enquête. Kinshasa, République Démocratique du Congo. Kinshasa. 2019.

37. Ministère du Plan et Suivi de la Mise en oeuvre de la Révolution de la Modernité (MPSMRM), Ministère de la Santé Publique, ICF International. Enquête Démographique et de Santé en République Démocratique du Congo 2013-2014. Rockville, Maryland. USA: MPSMRM, MSP et ICF International; 2014. https://dhsprogram.com/pubs/pdf/FR300/FR300.pdf Accessed 10 May 2021

38. Ngo T-T-D, Nguyen T-D, Goyens P, Robert A. Misuse of antenatal care and its association with adverse outcomes of pregnancy in a Southern rural area of Vietnam. Health Care Women Int. 2018;39(4):472-92. https://www.ncbi.nlm.nih.gov/pubmed/29111908 Accessed 10 May 2021

39. Babalola S. Women's Education Level, Antenatal Visits and the Quality of Skilled Antenatal Care: A Study of Three African Countries. J Health Care Poor Underser. 2014 ;25(1):161-79. 
http://search.proquest.com/docview/1503121491/abstract/374964B02E9F4EBCPQ/1 Accessed 10 May 2021

40. Barber SL, Bertozzi SM, Gertler PJ. Variations in prenatal care quality for the rural poor in Mexico. Health Aff Proj Hope. 2007;26(3):w310-323.

41. Geleto A, Chojenta C, Musa A, Loxton D. WOMEN's Knowledge of Obstetric Danger signs in Ethiopia (WOMEN's KODE):a systematic review and meta-analysis. Syst Rev. 2019;8. https://www.ncbi.nlm.nih.gov/pmc/articles/PMC6388496/ Accessed 10 May 2021

42. Akeju DO, Vidler M, Sotunsa JO, Osiberu MO, Orenuga EO, Oladapo OT, et al. Human resource constraints and the prospect of task-sharing among community health workers for the detection of early signs of pre-eclampsia in Ogun State, Nigeria. Reprod Health. 2016;13(2):111. https://doi.org/10.1186/s12978-016-0216-y Accessed 10 May 2021

43. Warren C, Salisu Ishaku, Ayodeji B O, Adoyi G, Karen R. K, Amy Dempsey. Landscaping analysis for pre-eclampsia and eclampsia in Nigeria. Abuja: Federal Capital Territory: Population Council; 2015 p. 36. http://www.endingeclampsia.org/wp-content/uploads/2017/04/EndingEclampsia-LandscapeReportNigeria.pdf Accessed 10 May 2021

\section{Tables}

Table 1: Characteristics of health facilities, providers and pregnant women 


\begin{tabular}{|c|c|}
\hline Characteristics & $\mathrm{n}(\%)$ \\
\hline \multirow{2}{*}{\multicolumn{2}{|c|}{$\begin{array}{l}\text { Health facility characteristics } \\
\text { Mean number of pregnant women attended per day }\end{array}$}} \\
\hline & \\
\hline Median(IQR) & $8(3-15)$ \\
\hline Range & 1 to 111 \\
\hline \multicolumn{2}{|l|}{ Facility type } \\
\hline Primary health centre & $319(36.9)$ \\
\hline Hospital & $545(63.1)$ \\
\hline \multicolumn{2}{|l|}{ Managing authority } \\
\hline Public & $534(61.8)$ \\
\hline Private & $330(38.2)$ \\
\hline \multicolumn{2}{|l|}{ Facility location } \\
\hline Urban & $231(26.7)$ \\
\hline Rural & $633(73.3)$ \\
\hline \multicolumn{2}{|c|}{ Health provider characteristics } \\
\hline \multicolumn{2}{|c|}{ Sex } \\
\hline Male & $380(31.9)$ \\
\hline Female & $811(68.1)$ \\
\hline \multicolumn{2}{|l|}{ Qualification } \\
\hline Midwive & $1039(87.2)$ \\
\hline Physician & $152(12.8)$ \\
\hline \multicolumn{2}{|c|}{ Received in-service training on any screening during ANC } \\
\hline Yes & $453(38.1)$ \\
\hline No & $736(61.9)$ \\
\hline \multicolumn{2}{|l|}{ Maternal characteristics } \\
\hline \multicolumn{2}{|l|}{ Residence } \\
\hline Rural & 2795 (74.3) \\
\hline Urban & $968(25.7)$ \\
\hline \multicolumn{2}{|l|}{ Schooling level } \\
\hline Primary or less & $2118(56.3)$ \\
\hline Secondary or above & 1645 (43.7) \\
\hline \multicolumn{2}{|l|}{ Gestational age (weeks) } \\
\hline Median (IQR) & $28(24-32)$ \\
\hline Range & 20 to 44 \\
\hline \multicolumn{2}{|l|}{ First pregnancy } \\
\hline Yes & $963(25.6)$ \\
\hline No & $2800(74.4)$ \\
\hline \multicolumn{2}{|l|}{ First antenatal visit } \\
\hline Yes & 2021 (53.7) \\
\hline No & $1742(46.3)$ \\
\hline
\end{tabular}

ANC: antenatal care; IQR: interquartile range

Table 2 : Weighted proportion of pregnant women who received antenatal services at the time of the survey, by province 


\begin{tabular}{|c|c|c|c|c|c|}
\hline Province & $\begin{array}{l}\text { Take woman's } \\
\text { blood } \\
\text { pressure n(\%) }\end{array}$ & $\begin{array}{c}\text { Ask } \\
\text { about } \\
\text { any sign } \\
n(\%)\end{array}$ & $\begin{array}{c}\text { Ask about } \\
\text { headache or } \\
\text { blurred vision } \\
n(\%)\end{array}$ & $\begin{array}{l}\text { Ask about } \\
\text { swollen } \\
\text { hands or } \\
\text { face } \\
n(\%)\end{array}$ & $\begin{array}{l}\text { Perform or } \\
\text { referred for } \\
\text { urine test } \mathrm{n}(\%)\end{array}$ \\
\hline $\begin{array}{l}\text { Bandundu } \\
(\mathrm{n}=265) \\
\text { Bas }\end{array}$ & $200(75.5)$ & $29(10.9)$ & $22(8.3)$ & $12(4.5)$ & $36(13.6)$ \\
\hline $\begin{array}{l}\text { Congo } \\
(105)\end{array}$ & 102(97.1) & $25(23.8)$ & $23(21.9)$ & $4(3.8)$ & $32(30.5)$ \\
\hline $\begin{array}{l}\text { Equateur } \\
\text { (559) } \\
\text { Kasai }\end{array}$ & $474(84.8)$ & $135(24.2)$ & $113(20.2)$ & $36(6.4)$ & $122(21.8)$ \\
\hline $\begin{array}{l}\text { Occidental } \\
(\mathrm{n}=130) \\
\text { Kasai }\end{array}$ & $89(68.5)$ & $19(14.6)$ & $7(5.4)$ & 15(11.5) & $9(6.9)$ \\
\hline $\begin{array}{l}\text { Oriental } \\
(\mathrm{n}=180)\end{array}$ & $112(62.2)$ & $32(17.8)$ & $25(13.9)$ & $8(4.4)$ & $7(3.9)$ \\
\hline $\begin{array}{l}(\mathrm{n}=626) \\
\text { Kinshasa }\end{array}$ & $460(73.5)$ & $162(25.9)$ & $102(16.3)$ & $84(13.4)$ & $143(22.8)$ \\
\hline $\begin{array}{l}\text { Kinshasa } \\
(n=275) \\
\text { Maniema }\end{array}$ & 217(78.9) & $84(30.5)$ & $63(22.9)$ & $37(13.5)$ & $99(36.0)$ \\
\hline $\begin{array}{l}(n=75) \\
\text { Nord Kivu }\end{array}$ & $27(36.0)$ & $6(8.0)$ & $6(8.0)$ & $3(3.9)$ & $10(13.3)$ \\
\hline $\begin{array}{l}(n=366) \\
\text { Sud Kivu }\end{array}$ & $325(88.8)$ & $141(38.5)$ & $128(35)$ & $76(20.8)$ & $75(20.5)$ \\
\hline $\begin{array}{l}(\mathrm{n}=824) \\
\text { Oriental }\end{array}$ & $696(84.5)$ & $140(17)$ & $110(13.3)$ & $84(10.2)$ & 137(16.6) \\
\hline $\begin{array}{l}(\mathrm{n}=358) \\
\text { Overall }\end{array}$ & $237(66.2)$ & $42(11.7)$ & $37(10.3)$ & $8(2.2)$ & $72(20.1)$ \\
\hline$(n=3763)$ & $2941(78.2)$ & $815(21.7)$ & $638(17.0)$ & $365(9.7)$ & 744(19.8) \\
\hline
\end{tabular}

Table 3: Weighted proportion of pregnant women screened for preeclampsia at the time of the survey by province and according to facility type and ownership 


\begin{tabular}{|c|c|c|c|c|c|c|}
\hline \multirow[t]{2}{*}{ Province } & \multicolumn{3}{|c|}{ Facility ownership } & \multicolumn{3}{|c|}{$\begin{array}{l}\text { Facility type } \\
\end{array}$} \\
\hline & $\begin{array}{l}\text { Public } \\
(\%)\end{array}$ & $\begin{array}{c}\text { Private } \\
\text { (\%) }\end{array}$ & $\begin{array}{c}\text { Weighted X } \\
\text { P-value }\end{array}$ & $\begin{array}{l}\text { Primary health } \\
\text { center(\%) }\end{array}$ & $\begin{array}{l}\text { Hospital } \\
(\%)\end{array}$ & $\begin{array}{c}\text { Weighted } \\
\mathrm{X} \square \mathrm{P}- \\
\text { value }\end{array}$ \\
\hline $\begin{array}{l}\text { Bandundu } \\
(\mathrm{n}=265)\end{array}$ & 7.6 & 21.4 & 0.042 & 7.8 & 10.7 & 0.54 \\
\hline $\begin{array}{l}\text { Bas Congo } \\
(n=105)\end{array}$ & 20.0 & 23.1 & 0.78 & 12.6 & 27.9 & 0.28 \\
\hline Equateur $(n=559)$ & 23.9 & 11.5 & 0.12 & 22.2 & 16.1 & 0.27 \\
\hline $\begin{array}{l}\text { Kasai Occidental } \\
(n=130)\end{array}$ & 12.1 & 4.5 & 0.23 & 8.7 & 10.9 & 0.72 \\
\hline $\begin{array}{l}\text { Kasai Oriental } \\
(n=180)\end{array}$ & 14.7 & 8.3 & 0.41 & 11.2 & 15.0 & 0.63 \\
\hline Katanga $(n=626)$ & 12.5 & 28.2 & 0.023 & 16.6 & 34.4 & 0.009 \\
\hline Kinshasa $(n=275)$ & 22.0 & 29.8 & 0.59 & 25.9 & 33.2 & 0.44 \\
\hline Maniema $(n=75)$ & 8.4 & 1.6 & 0.12 & 3.1 & 21.0 & 0.07 \\
\hline $\begin{array}{l}\text { Nord Kivu } \\
(\mathrm{n}=366)\end{array}$ & 34.2 & 42.1 & 0.71 & 46.4 & 22.1 & 0.14 \\
\hline Sud Kivu $(\mathrm{n}=824)$ & 21.1 & 13.8 & 0.44 & 16.8 & 16.1 & 0.93 \\
\hline Oriental $(n=358)$ & 9.5 & 10.7 & 0.84 & 7.3 & 17.1 & 0.08 \\
\hline Overall $(n=3763)$ & 17.4 & 21.5 & 0.29 & 18.5 & 21.6 & 0.30 \\
\hline
\end{tabular}

Table 4: Factors associated with screening for preeclampsia in 3763 pregnant women attending antenatal care in 864 clinics of DR Congo, using GEE logistic regression model 
no./N (\%)

First pregnancy

$$
\text { Yes }
$$

No

Schooling

Primary or less

Secondary or more

First ANC visit

$$
\text { Yes }
$$

No

Location

Rural area

Urban area

Facility ownership

Private

Public

Facility type

PHCs

Hospitals

Type of health providers

\section{Midwife}

Physician

$49 / 176(27.8)$
$169 / 963$ (17.6)

$549 / 2800(19.6)$

$380 / 2118(17.9)$

$338 / 1645$ (20.6)

$317 / 1742$ (18.2)

402/2021 (19.9)

$317 / 1742(18.2)$
$402 / 2021(19.9)$

Crude OR

(95\% IC) Value
Adjusted

OR $(95 \%$ Value

IC)

0.69

1

1.10(0.84-

$$
\text { 1.45) }
$$

508/2795 (18.2)

211/968 (21.8)

\section{1}

1.26(1.09-

1.47)
0.002

\section{1}

1.21(1.04-

1.42)

$<0.001$

1

1.32(1.14-

1.52)
$<0.001$

1

$1.39(1.20-$

1.62)
0.016

0.002

1

1.52(1.16-

1.98)

1.37(1.06-

1.76)

1
0.036

\section{1}

1.36(1.02-

1.82)

0.014

$1.22(0.94-$

1.59)

$382 / 2193$ (17.4)

$553 / 2996$ (18.5)

166/767 (21.6)

1

1.20(0.93-

1.56)

0.17

0.58

\section{1}

$1.08(0.82-$

$1.41)$

\subsection{6}

0.69

Mean number of pregnant women attended per

day

Women attended by health provider who

$670 / 3587(18.7)$
1

$1.35(0.99-$

1.83)

$0.85(073-$

0.99 )

received in-service training in ANC screening

within the previous 2 years

Yes

$351 / 1436$ (24.4)

No

368/2327 (15.8)

Province of residence ${ }^{\#}$

Middle

Eastern

$33 / 310(10.7)$

285/1265 (22.5)

Southern

123/626 (19.7)

Western

$122 / 645$ (18.9)

Northern

155/916 (17.0)

0.006 1

2.18(1.132.99)

$2.20(1.10-$ $4.41)$

1.79(0.88$3.61)$

1.71(0.863.39)

0.005

1

2.28(1.37-

$3.76)$

2.05(1.25-

$3.34)$

1.98(1.24-

3.18)

1.45(0.90-

Abbreviations: GEE Generalized estimating equations; OR Odds ratio; HDP Hypertensive 
disorders in pregnancy; yrs years; wks weeks

\# Provinces were categorized according to their geographic location into Center (Kasai Occidental and Kasai Oriental), Northern (Equateur and Oriental), Western (Bas Congo, Bandundu and Kinshasa), Southern (Katanga), and Eastern (Maniema, Nord Kivu and Sud Kivu).

\section{Figures}




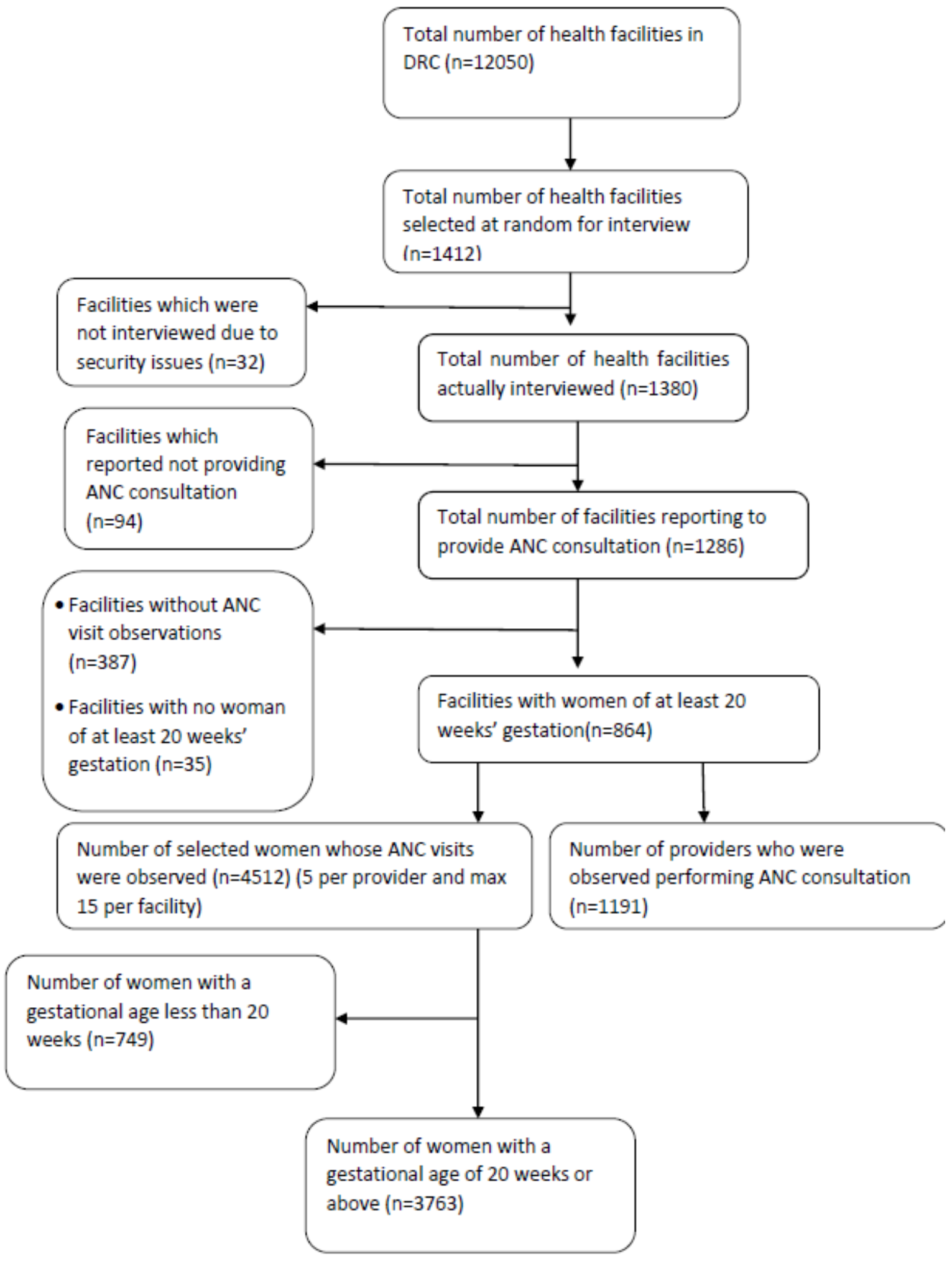

\section{Figure 1}

Selection procedure for the sampling units included in this analysis ANC: Antenatal care 


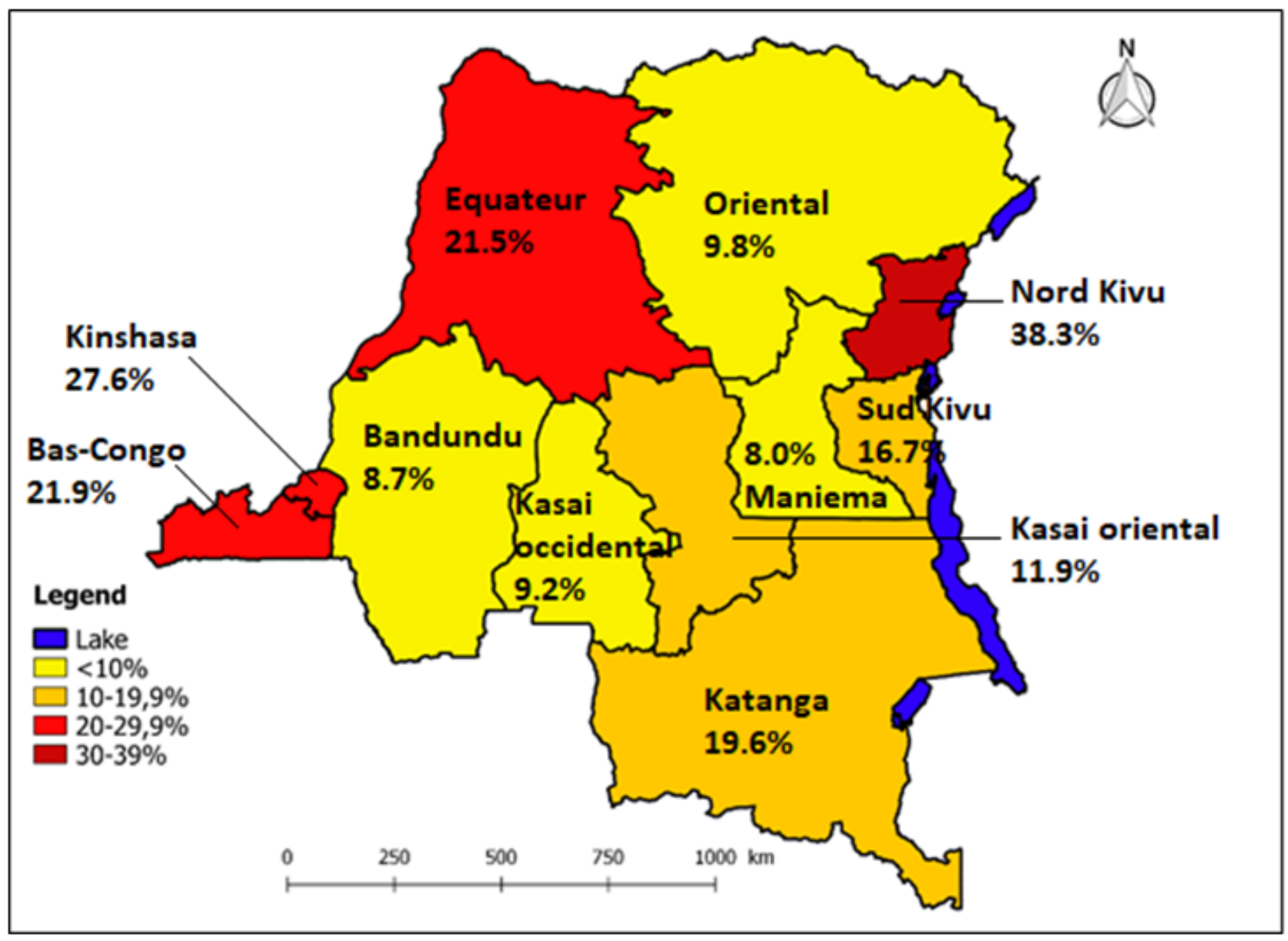

Figure 2

Weighted proportion of pregnant women screened for preeclampsia during antenatal care visit in DRC, by province A pregnant woman was considered as screened for preeclampsia if she received a blood pressure measurement, and an assessment for warning signs of preeclampsia. 